\title{
Alterations of glycosaminoglycan disaccharide content and composition in colorectal cancer: Structural and expressional studies
}

\author{
DIMITRIOS KALATHAS ${ }^{1}$, DIMITRIOS A. THEOCHARIS ${ }^{2}$, DIMITRIOS BOUNIAS $^{3}$, DORA KYRIAKOPOULOU ${ }^{3}$, \\ NIKOLETTA PAPAGEORGAKOPOULOU ${ }^{1}$, MICHAEL S. STAVROPOULOS ${ }^{3}$ and DEMITRIOS H. VYNIOS ${ }^{1}$ \\ ${ }^{1}$ Department of Chemistry, Laboratory of Biochemistry, Section of Organic Chemistry and Natural Products, \\ ${ }^{2}$ Laboratory of Biological Chemistry, School of Medicine, University of Patras; ${ }^{3}$ Department of Surgery, \\ School of Medicine and University Hospital, 26110 Patras, Greece
}

Received February 3, 2009; Accepted April 14, 2009

DOI: $10.3892 /$ or_00000447

\begin{abstract}
The glycosaminoglycans are implicated in many processes important in the growth and progression of malignant tumors. In the present study glycosaminoglycans were purified from healthy, macroscopically normal and cancerous specimens of different anatomic sites and different stages of cancer and analyzed by FACE after chondroitinases and sulfatases digestion. The cancerous samples contained increased levels of 6-sulfated unsaturated disaccharides compared to macroscopically normal and healthy samples, the increase being stage-related. The differences in sulfation were found to be related to the anatomic site and the stage of cancer. RT-PCR analysis of 4-sulfotransferase mRNA revealed its presence in decreasing amounts as the stage of the cancer increased. Furthermore, the percent content of hyaluronan disaccharides was elevated in macroscopically normal samples compared to the cancerous, and in addition,
\end{abstract}

Correspondence to: Dr Demitrios H. Vynios, Department of Chemistry, Laboratory of Biochemistry, Section of Organic Chemistry and Natural Products, University of Patras, 26110 Patras, Greece

E-mail: vynios@chemistry.upatras.gr

Abbreviations: CS, chondroitin sulfate; DS, dermatan sulphate; HS, heparan sulphate; GalAGs, galactosaminoglycans; GAGs, glycosaminoglycans; HA, hyaluronan; PGs, proteoglycans; $\Delta$ dinon- $\mathrm{S}_{\mathrm{HA}}$, 2-acetamido-2-deoxy-3-O-(4-deoxy-B-L-threo-hex-4enopyranosyluronic acid)-D-glucose; $\Delta$ di-non- $\mathrm{S}_{\mathrm{CS} / \mathrm{DS}}, 2$-acetamido-2deoxy-3-O-(4-deoxy-ß-L-threo-hex-4-enopyranosyluronic acid)-Dgalactose; $\Delta$ di-mono4S, 2-acetamido-2-deoxy-3-O-(4-deoxy-B-Lthreo-hex-4-enopyranosyluronic acid)-D-galactose-4-sulfate; $\Delta$ dimono6S, 2-acetamido-2-deoxy-3-O-(4-deoxy-ß-L-threo-hex-4enopyranosyluronic acid)-D-galactose-6-sulfate; D4ST1, dermatan4-sulfotransferase; CHST3, chondroitin-6-sulfotransferase

Key words: hyaluronan, chondroitin sulfate, dermatan sulfate, cancer stage, sulfotransferases it was much more elevated than that of healthy samples. Haluronan levels increase with stage in cancerous tissues. Therefore, it could be concluded that the glycosaminoglycans in colorectal cancer are biosynthetically directed to contribute in different ways depending on the cancer stage and anatomical site.

\section{Introduction}

Glycosaminoglycans comprise a class of molecules composed by repeating disaccharide units of uronic acid and hexosamine. There are four major types of glycosaminoglycans (GAGs), namely hyaluronan (HA), chondroitin sulfate (CS) and dermatan sulfate (DS), heparin (Hep) and heparan sulfate (HS) and keratan sulfate (KS). GAGs are highly anionic polysaccharides present in the extracellular matrix (ECM) and the cells. The biological importance of their fine structures in normal and disease state has been well demonstrated (1). They seem to play several roles in tumor formation because of their capacity to bind and modulate the action of a variety of proteins including growth factors, cytokines, and proteases. Much research has focused on glycosaminoglycans in a variety of tumors of mainly the gastrointestinal tract. In poorly differentiated tumors a great increase of hyaluronan and $\Delta$ di-mono6S has been observed (2). Additionally, non-sulfated chondroitin is detected in cancerous tissues, which is almost absent in normal specimens. Furthermore, the total content of chondroitinase ABC resistant GAGs in cancerous tissues is decreased compared to the normal ones (2) and differences in the sulfation pattern of Hep are also described (3). In adenomas, HS contains more sulfate groups than in carcinomas. In carcinomas, the lower sulfation is due to reduction in $\mathrm{N}$-sulfation $(20 \%)$ and 2-O-sulfation $(33 \%)$. An increase in 6-O-sulfation $(24 \%)$ cannot offset the decrease in $\mathrm{N}$ - and $\mathrm{O}$-sulfation.

Biosynthesis of sulfated GAGs is the final event during proteoglycan biosynthesis and proceeds within few minutes. Glycosyl- and sulfo-transferases are acting in parallel to form the structure(s) required by the cells to express their functions. It has been proposed that during cancer formation and growth, the rapid biosynthetic rate of the cells is responsible for the 
observed low sulfation of the GAGs. The different sulfation pattern of the GAGs observed in various cancers of epithelial origin (4) cannot be explained by a similar manner and a differential expression of sulfotransferases would be adapted. However, there is no evidence till now for such a differential expression and this point remains unclear.

It is also supposed that cancer growth proceeds via different mechanisms through the different stages. Furthermore, it is not known whether the GAGs profile is similar in tumors of different anatomic sites of colon. Therefore, the study of GAG alterations in these conditions is very important and that was the aim of the present study. The structure of GAGs was examined by fluorophore assisted carbohydrate electrophoresis (FACE) of their disaccharides produced after chondroitinase treatment of the papain lysate of the tissues. In addition, the expression of dermatan sulfate-specific 4sulfotransferase (D4ST-1) which is the sixth member of the HNK-1 family of sulfotransferases and chondroitin-6sulfotransferase (CHST3) were examined to further explain the results of FACE analysis.

\section{Materials and methods}

Chemicals. Papain 2 x crystallized (EC 3.4.22.2), chrondroitinase ABC (EC 4.2.2.4), chondro-6-sulfatase (EC 3.1.6.10) were obtained from Sigma (St. Louis, MO, USA). Chondro4-sulfatase (EC 3.1.6.9) was purchased from Seikagaku Corp. (Tokyo, Japan) and 2-aminoacridone was from Fluka Chemie (Steinheim, Germany). All other reagents used were of the best available grade.

Tissue origin. Tissues were obtained from patients after surgical excision for colon or rectal carcinoma. Specimens were washed with $0.15 \mathrm{M} \mathrm{NaCl}$ and the tissues were separated from the fat. From each examined patient two different specimens were obtained: one cancerous, from the center of the tumor, and one neighbouring macroscopically normal. Healthy tissue was obtained from a 26-year-old donor. The study design was approved by the Ethics Committee of the University Hospital of the University of Patras.

Isolation of GAGs. Tissue specimens were digested with $2 \mathrm{x}$ crystallized papain (28 units/g of wet tissue) for $24 \mathrm{~h}$ at $60^{\circ} \mathrm{C}$ in $0.1 \mathrm{M}$ Tris-acetate $\mathrm{pH} 7.2$ buffer containing $5 \mathrm{mM}$ $\mathrm{K}_{2}$ EDTA and $5 \mathrm{mM}$ cysteine hydrochloride. Enzyme was first activated in the buffer for $30 \mathrm{~min}$ at $37^{\circ} \mathrm{C}$. The enzyme was renewed after $24 \mathrm{~h}$ of digestion and the proteolysis was terminated the next $24 \mathrm{~h}$ by heating at $100^{\circ} \mathrm{C}$ for $5 \mathrm{~min}$. The samples were then centrifuged $(5,000 \mathrm{rpm}$ for $5 \mathrm{~min})$ and the supernatants containing the liberated GAGs were stored at $-20^{\circ} \mathrm{C}$.

Fluorophore assisted carbohydrate electrophoresis (FACE). FACE analysis was performed according the method described by Karousou et al (5). The papain digests were purified by precipitation with 4.3 vols of $95 \%$ ethanol, saturated with sodium acetate. The samples mixed vigorously, vortexed and stored overnight at $4^{\circ} \mathrm{C}$. They were then centrifuged at $10,000 \mathrm{x} \mathrm{g}$ for $15 \mathrm{~min}$ at $4^{\circ} \mathrm{C}$ to pellet any macromolecules,
Table I. Nucleotide sequence of the primers used in RT-PCR experiments.

\begin{tabular}{lc}
\hline Type of primer & \multicolumn{1}{c}{ Nucleotide sequence } \\
\hline Sense & \\
4-sulfotransferase & ACTGGAAGCGGGTGATGAAGG \\
6-sulfotransferase & CATATCAAGGGTCTCAGACAAGC \\
GAPDH & TCAACGGATTTGGTCGTATTGGG \\
Antisense & \\
4-sulfotransferase & AAATCGGACGTGAGGTGGTGC \\
6-sulfotransferase & GTACAGGTCGCACAGGAAGAG \\
GAPDH & GACTCCACGACGTACTCAGC \\
\hline
\end{tabular}

and the supernatants were discarded. The samples containing GAGs were dissolved in $100 \mathrm{mM}$ ammonium acetate, $\mathrm{pH} 7.0$, containing $200 \mathrm{mU} / \mathrm{ml}$ chondroitinase $\mathrm{ABC}$ or a combination of the latter enzyme with $100 \mathrm{mU} / \mathrm{ml}$ chondro-4 or chondro6-sulphatase and digested for $20 \mathrm{~h}$ at $37^{\circ} \mathrm{C}$. Then, all samples were frozen at $-80^{\circ} \mathrm{C}$ and dried on a vacuum concentrator prior to derivatization with $5 \mu 1$ of 2 -aminoacridone (AMAC) in $\mathrm{DMSO} / \mathrm{CH}_{3} \mathrm{COOH}(85 / 15)$ for $15 \mathrm{~min}$ at $37^{\circ} \mathrm{C}$. The Schiff base formed was reduced by incubation with $5 \mu 1$ of $1 \mathrm{M}$ $\mathrm{NaBH}_{3} \mathrm{CN} 37^{\circ} \mathrm{C}$ for $16 \mathrm{~h}$. After adding $20 \%$ glycerol (final concentration) the samples were stored at $-80^{\circ} \mathrm{C}$ until analysis.

RT-PCR analysis. Macherey-Nagel total RNA isolation kit (Düren, Germany) was used for total RNA tissue isolation according to manufacturer's instructions. Total RNA (40 ng) isolated from the cancerous and macroscopically normal tissues and $100 \mathrm{ng}$ of total RNA of the healthy tissues was used to perform the RT-PCR experiments. The primers used (illustrated in Table I) were designed using a free software (PerlPrimer v1.1.14). Takara one step RT-PCR kit was used to perform the analysis. The conditions of RT-PCR are as follows: reversed transcription was performed at $50^{\circ} \mathrm{C}$ for $30 \mathrm{~min}$ and then Taq polymerase was activated at $94^{\circ} \mathrm{C}$ for $2 \mathrm{~min}$, followed by 35 amplification cycles $\left(94^{\circ} \mathrm{C}\right.$ for $30 \mathrm{sec}$, $58^{\circ} \mathrm{C}$ for $30 \mathrm{sec}$ and $72^{\circ} \mathrm{C}$ for $1 \mathrm{~min}$ ) and $10 \mathrm{~min}$ at $72^{\circ} \mathrm{C}$. RT-PCR products were separated by gel electrophoresis on $2 \% \mathrm{w} / \mathrm{v}$ agarose gel containing SYBR Gold stain to visualize the bands under UV. The gels were then scanned and the bands were analyzed densitometrically. Quantitative differences between cDNA samples were normalized by including GAPDH in all experiments.

\section{Results}

Disaccharide composition. We have examined the disaccharide profile in tissues of various stages of cancers from different anatomic sites of large intestine, the pathologic characteristics of which are shown in Table II. The disaccharides were obtained after treatment with chondroitinase $\mathrm{ABC}$ or in combination with chondro- 4 or chondro-6-sulfatase to increase the reliability of the results. The analysis of the disaccharides was performed after AMAC derivatization and 
Table II. Characteristics of the patients.

\begin{tabular}{|c|c|c|c|c|c|c|}
\hline No. & Age & Sex & Location $^{\mathrm{a}}$ & $\mathrm{LN}^{\mathrm{b}}$ & Stage & $\mathrm{A} / \mathrm{C}$ stage $^{\mathrm{c}}$ \\
\hline 1 & 72 & $\mathrm{M}$ & $\mathrm{S}$ & $\mathrm{N} 2$ & IV & $\mathrm{D}$ \\
\hline 2 & 80 & $\mathrm{M}$ & $\mathrm{C}$ & N1 & IV & $\mathrm{C} 2$ \\
\hline 3 & 80 & $\mathrm{~F}$ & A & N1 & III & $\mathrm{C} 2$ \\
\hline 4 & 70 & $\mathrm{~F}$ & A & N1 & III & $\mathrm{C} 1$ \\
\hline 5 & 87 & $\mathrm{M}$ & $\mathrm{C}$ & N1 & III & $\mathrm{C} 1$ \\
\hline 6 & 80 & $\mathrm{M}$ & $\mathrm{C}$ & N1 & III & $\mathrm{C} 1$ \\
\hline 7 & 62 & $\mathrm{~F}$ & $\mathrm{~S}$ & NO & I & B1 \\
\hline 8 & 61 & $\mathrm{M}$ & $\mathrm{R}$ & N0 & I & B1 \\
\hline 9 & 73 & $\mathrm{M}$ & $\mathrm{D}$ & NO & II & B2 \\
\hline 10 & 84 & $\mathrm{~F}$ & $\mathrm{~S}$ & NO & II & B2 \\
\hline 11 & 85 & $\mathrm{M}$ & $\mathrm{C}$ & NO & II & B2 \\
\hline 12 & 82 & M & $\mathrm{C}$ & NO & II & B2 \\
\hline 13 & 82 & M & $\mathrm{T}$ & NO & II & B2 \\
\hline 14 & 45 & $\mathrm{M}$ & $\mathrm{T}$ & NO & II & B2 \\
\hline 15 & 65 & $\mathrm{M}$ & $\mathrm{R}$ & N0 & II & B2 \\
\hline 16 & 81 & $\mathrm{M}$ & $\mathrm{R}$ & NO & II & B2 \\
\hline 17 & 76 & M & $\mathrm{S}$ & NO & I & B1 \\
\hline
\end{tabular}

${ }^{a}$ Location of primary tumor. A, ascending colon; C, cecum; D, descending colon; R, rectum; S, sigmoid colon; T, transverse colon. ${ }^{b} \mathrm{LN}$, lymph node metastasis. ${ }^{\mathrm{c}}$ According to Astler-Coller staging.


Figure 1. Glycosaminoglycan $\Delta$-disaccharide profile in healthy, normal and cancerous tissues. Upper panel, a typical profile of $\Delta$-disaccharides obtained from the macroscopically normal $(\mathrm{N})$ and cancerous $(\mathrm{C})$ specimens of a patient after digestion with chondroitinase $\mathrm{ABC}(\mathrm{ChABC})$ alone or after mixing with either 4-sulfatase (4S) or 6-sulfatase (6S), derivatization with AMAC and electrophoretic separation of the products. std, reference $\Delta$-disaccharides; $\mathrm{HA}, \Delta$ di-non-S $\mathrm{HA}_{\mathrm{HA}}$; C0S, $\Delta$ di-non-S $\mathrm{CS}_{\mathrm{CS}} ; \mathrm{C} 6 \mathrm{~S}, \Delta$ di-mono6S; C4S, $\Delta$ di-mono4S; C2S, $\Delta$ di-mono2S. Lower panel, semi-quantitave presentation of the FACE analysis results. White boxes, healthy; grey boxes, macroscopically normal; black boxes, cancerous. gel electrophoresis. A typical figure of the results obtained is shown in Fig. 1, upper panel.

The total glycosaminoglycan disaccharide profile indicated that the absolute amounts of $\Delta$ di-non- $\mathrm{S}_{\mathrm{HA}}$ and $\Delta$ di-mono6S were highly increased in the specimens of cancer patients as compared with those of healthy specimens (Fig. 1, lower panel). HA was increased 2.5-times in the normal and 5.5times in cancerous and $\Delta$ di-mono $4 \mathrm{~S}$ was increased about equally (1.5-times) in both normal and cancerous samples. On the other hand $\Delta$ di-mono6S was found to be substantially elevated (the mean value was increased $\sim 2.5$-times) only in the cancerous specimens. Furthermore, $\Delta$ di-non- $\mathrm{S}_{\mathrm{CS} / \mathrm{DS}}$ was detected only in the cancerous parts of the specimens obtained from the patients (Fig. 1, lower panel).

The sulfation pattern was found to depend on the stage of cancer (Fig. 2). In almost all cases, the specimens of the patients contained increased amounts of glycosaminoglycan disaccharides, compared to the healthy. $\Delta$ di-non- $\mathrm{S}_{\mathrm{HA}}$ was found to be increased in the cancerous parts from stage I up to stage III, thereafter, at stage IV, it was slightly decreased (Fig. 2A). However, in the macroscopically normal parts, high amounts of $\Delta$ di-non- $\mathrm{S}_{\mathrm{HA}}$ were observed at stages I and III (Fig. 2A), being higher to those of the respective cancerous parts. It should be noted here that $\Delta$ di-non- $S_{\mathrm{HA}}$, when expressed as percentage of total chondroitinase $\mathrm{ABC}$ sensitive disaccharides, was found to be higher in the macroscopically normal specimens than in the respective cancerous (data not shown), in agreement with previous findings (2). A slightly different figure was obtained in the case of $\Delta$ di-mono6S. Its amounts measured in the specimens of the patients were higher to those found in the healthy, but not so much as in the case of $\Delta$ di-non- $\mathrm{S}_{\mathrm{HA}}$. The amounts of $\Delta$ di-6S observed in the 

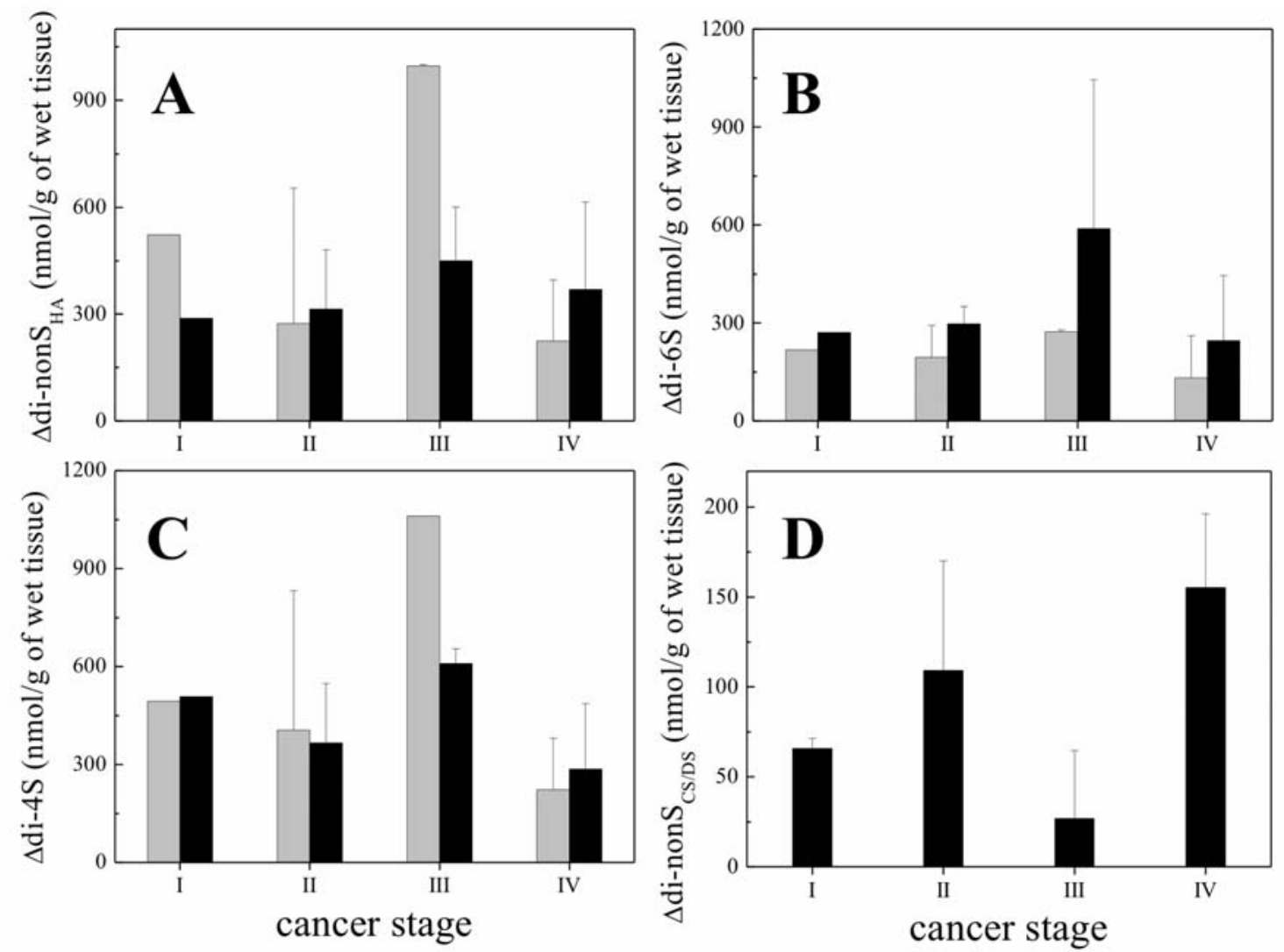

Figure 2. Stage related changes in $\Delta$-disaccharide content. The samples were degraded with chondroitinase $\mathrm{ABC}$ and the $\Delta$-disaccharides obtained were derivatized with AMAC and subjected to FACE analysis. (A) $\Delta$ di-non- $\mathrm{S}_{\mathrm{HA}}$; (B) $\Delta$ di-mono6S; (C) $\Delta$ di-mono4S; (D) $\Delta$ di-non-S $\mathrm{S}_{\mathrm{CSIDS}}$.
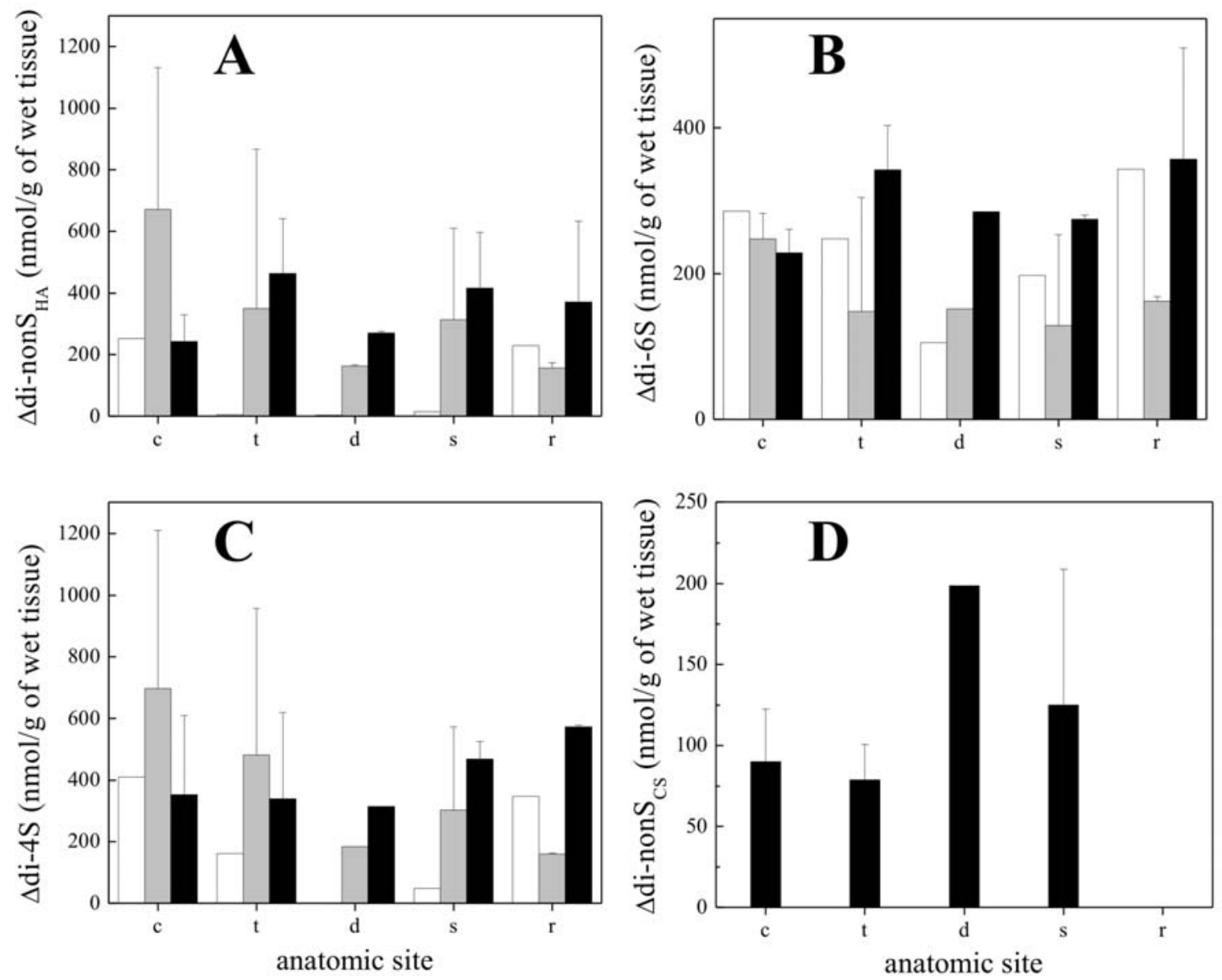

Figure 3. Anatomic site related changes in $\Delta$-disaccharide content. For details, see Fig. 2. c, cecum; t, transverse; d, descending; s, sigmoid; r, rectum. 
cancerous parts followed a stage-related increase with the exception of stage IV, and they were higher to those of the macroscopically normal parts of all stages (Fig. 2B). A quite different figure was obtained in the case of $\Delta$ di-mono $4 S$, where its amounts were found to be increased in stage I, compared to healthy. Thereafter $\Delta$ di-mono $4 \mathrm{~S}$ amounts showed a tendency to become lower as the stage of cancer increased (Fig. 2C), with the exception of stage III, a result that might be due to the samples analyzed. On the other hand, $\Delta$ di-non$\mathrm{S}_{\mathrm{CS} / \mathrm{DS}}$ amounts, being present in measurable amounts only in cancerous specimens, showed a tendency to become higher as the stage of the cancer increased (Fig. 2D).

The sulfation pattern was also found to depend on the anatomic site of cancer (Fig. 3). In healthy tissues, $\Delta$ di-non- $S_{\mathrm{HA}}$ was present in trace amounts in transverse, descending and sigmoid colon and in measurable amounts in cecum and rectum. During cancer development, $\Delta$ di-non- $\mathrm{S}_{\mathrm{HA}}$ amounts were highly increased, especially in the cancerous parts of the tissues, with the exception of cecum (Fig. 3A). In a similar manner, $\Delta$ di-mono6S and $\Delta$ di-mono4S were present in lower amounts in transverse, sigmoid and especially descending colon, as compared with cecum and rectum (Fig. 3B and $\mathrm{C}$ ), and were increased in cancer. It should be noted that in all anatomic sites, $\Delta$ di-mono6S amounts in cancerous parts were double to those in macroscopically normal, with the exception of cecum, where about equal amounts were measured (Fig. 3B). On the other hand, $\Delta$ di-mono4S amounts in cancerous parts of cecum and transverse colon were lower than in macroscopically normal, but higher in descending, sigmoid and especially in rectum, being about 3-times more (Fig. 3C). $\Delta$ di-non- $\mathrm{S}_{\mathrm{CS}}$ was present in about equal amounts in cecum, transverse and sigmoid colon and in about double amounts in descending colon, whereas it was almost absent in rectum (Fig. 3D).

Expression of 4- and 6-sulfotransferases. The differences in sulfated disaccharide composition should be attributed to altered activity or expression of the sulfotransferases. Since one of the most characteristic observations in colon cancer is a stage-related decrease in $\Delta$ di-mono $4 \mathrm{~S}$, the expression of the enzyme that contributes to $\mathrm{C}-4$ sulfation of $\mathrm{N}$-acetylgalactosamine (D4ST-1) was examined. The results obtained indicated a stage-related decrease in the expression of this specific enzyme in both macroscopically normal and cancerous tissues (Fig. 4A). This finding was in good agreement with the obtained $\Delta$ di-mono $4 \mathrm{~S}$ profile. It should be noted that a substantial increase of expression of the enzyme was observed in stage I compared to healthy and in late stages of cancer it was decreased to lower than in the healthy (Fig. 4A, inset). On the other hand, the expression of 6-sulfotransferase did not show considerable differences between the various stages of cancer (Fig. 4B). However, its expression was highly increased in cancer compared to healthy subjects (Fig. 4B, inset).

\section{Discussion}

Colorectal cancer is a very common disease in the developed world. The elucidation of the mechanisms of its development, growth, invasion and metastasis is very important because it
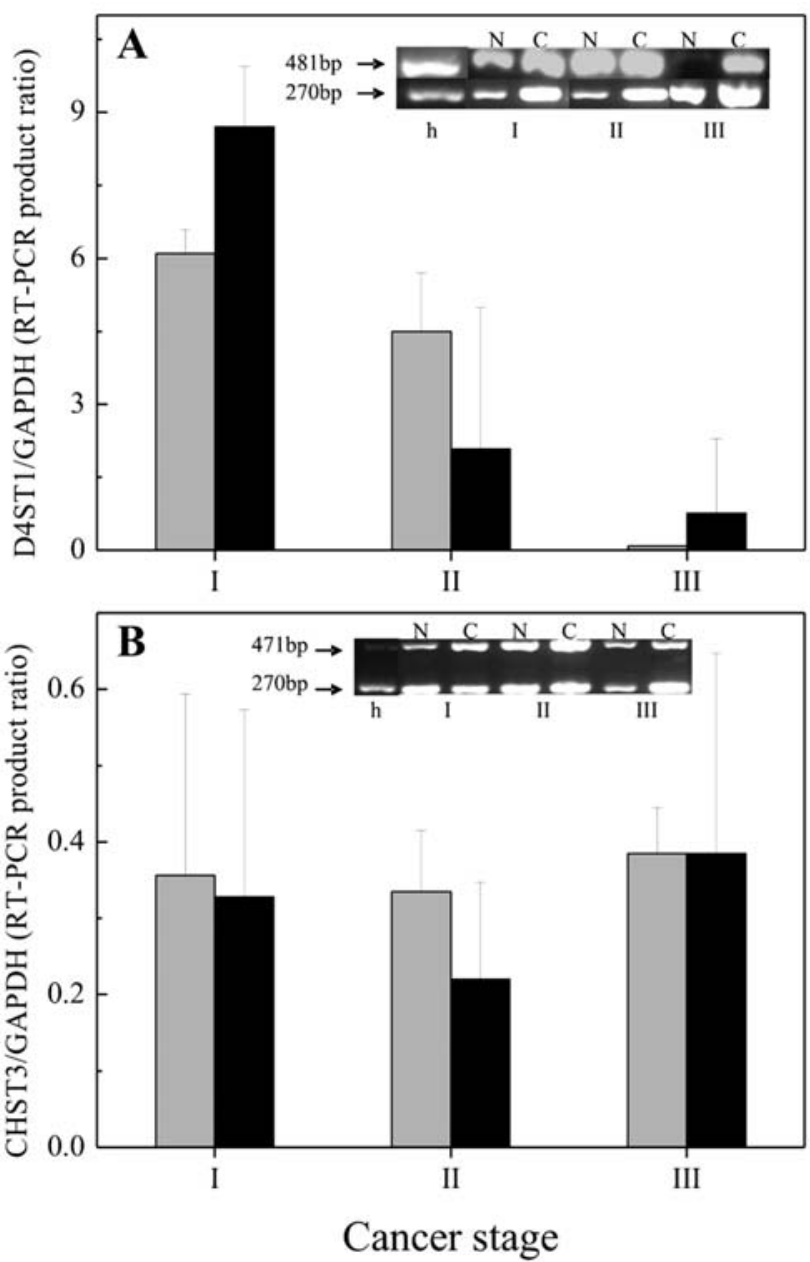

Figure 4. Stage related alterations in sulfotransferase expression. (A) 4-sulfotransferase. (B) 6-sulfotransferase. Insets, typical figure of the agarose electrophoresis separation of the respective RT-PCR products.

may lead to better prevention and more effective treatment. The aim of the present study was the characterization of GAG disaccharides in human colorectal cancer in relation with the stage and the anatomic site of cancer. Any alterations in the sulfate pattern of the GAG chains should be attributed to either enzymatic activities or substrates content. Therefore, the expression of the glycosaminoglycan modifying enzymes the dermatan sulfate-specific 4-sulfotransferase and chondroitin-6-sulfotransferase were examined to obtain a clearer picture of the alterations observed during the disease.

In healthy tissue, about equivalent amounts of 6- and 4sulfated CS/DS were found. In certain anatomic sites (such as rectum and cecum) increased amounts of HA were observed and this should be attributed to various reasons. Rectum is a tissue with increased ECM and cecum is a rigid structure because of the presence of ileum. Increased HA levels in certain anatomic sites of healthy tissues might be a reason for the increased risk of carcinogenesis. Colorectal carcinoma appears more frequently in rectum, sigmoid and cecum (6). In contrast carcinomas in transverse and descending colon are rare.

The predominant glycosaminoglycans in colorectal cancer samples are HA and CS/DS. Our experiments agreed with 
these observations and it was additionally found that the amounts of these GAGs were also increased in macroscopically normal parts of the tissue. It is interesting to note that the amounts of HA were highly increased in samples of stages I and III. The increase of HA amounts is a common phenomenon in all malignancies. It has been proposed that increased levels of HA correlates with aggressiveness of the cancer and poor prognosis. Continued exposure of cells in HA leads to cell proliferation and migration and decreases their differentiation rate. In fact, poorly differentiated tissues seem to possess higher levels of HA (2). It is well documented that the properties of HA are a function of its molecular weight (7). During the initial stages of cancer high molecular weight $\mathrm{HA}$ is required to provide the hydrated environment and thus to facilitate the diffusion of nutrients in the tumor site. When the tumor has developed and simple diffusion is not enough to feed the tumor, HA chains of middle molecular weight appear to facilitate the process of angiogenesis. It is noteworthy that HA is considered as a key molecule implicated in the invasive growth of carcinomas (4). In addition, tumor suppression can be proceed by HA chains smaller than ten disaccharide units. These findings imply that HA is possibly not only a cancer promoting molecule; it can participate in the defensive mechanism of the cell against tumor development. The critical point for its action is its size that depends on the hyaluronidase and HA synthase activity (7). The increased amounts of HA found in cecum could be explained by the aggressiveness of cancer in that anatomic site, however, its molecular mass is not known to support this hypothesis. A similar explanation might be followed for the increased HA amounts observed in macroscopically normal parts of stage I and III specimens, where a hyaluronan-rich milieu is required for cancer growth (stage I) and invasion (stage III).

The predominance of CS/DS in the samples examined was accompanied by structural variations. The detection of $\Delta$ di-non- $S_{\mathrm{CS}}$ was a characteristic finding of the present study and its presence in measurable amounts was observed in all anatomic sites examined with the exception of the rectum. Undersulfated CS/DS is a GAG of small hydrodynamic size usually present in cancer that contributes to a more malignant phenotype (8). In addition, an increase in absolute amounts of $\Delta$ di-mono6S together with a decrease of $\Delta$ di-mono $4 S$ was noted, both having a stage-related order. Previous studies have indicated the increase in $\Delta$ di-mono6s in cancerous tissues compared to the normal ones especially in poorly differentiated tissues. This increased presence of $\Delta$ di-mono6S correlates with the aggressiveness of tumor cells (2).

For deeper understanding and better explanation of these structural variations of CS/DS in colorectal cancer the expression of specific sulfotransferases was examined. The levels of 4-sulfotransferase in cancerous specimens were decreased and the decrease was related with cancer stage. These findings were in close agreement with the $\Delta$ di-mono $4 \mathrm{~S}$ profiles obtained by FACE analysis. On the other hand, the expression of 6-sulfotransferase did not show considerable differences in cancer. These observations suggested that the differential sulfation pattern observed in various cancers $(2,9-14)$ is not due to the rapid biosynthetic rate of the cells, in other words, a wrong biosynthesis from the cells, but a well-controlled process to provide the cellular prerequisites, which in the case of cancer might be described as a microenvironment facilitating cell proliferation and migration. It is noteworthy that this 4-sulfotransferase transfers sulfate specifically in DS and this provides additional evidence that its decreased expression offers a cancer-promoting environment. It should be noted here that both sulfotransferase expression were increased in stage I samples compared to healthy indicating the offensive mechanism of cancer (biosynthesis of chondroitin-6-sulfate) and the defensive mechanism of the tissue (biosynthesis of dermatan sulfate), but thereafter and since the cancer prevailed, the expression of 4-sulfotransferase substantially decreased.

The study of biosynthetic enzymes is of great importance, especially in cancer, as they can be used as tumor markers or drug targets. Decreased expression of D-glucuronyl C5epimerase (GLCE), another enzyme of GAG biosynthesis that acts on newly synthesized HS and Hep chains, was observed in breast cancer (15). In addition, chondroitin Dglucuronyl C5-epimerase (DSE), an enzyme acting exclusively on CS chains to transform them to DS, was identified as a characteristic squamous cell carcinoma antigen $(16,17)$. Since the 4-sulfotransferase studied in the present work acts exclusively on DS chains, it would be of great importance to examine DSE expression in colon cancer, and also the expression of both DSE and 4-sulfotransferase in breast cancer. It could also be informative to examine the expression of 4-sulfotransferase in squamous call carcinomas and to compare it to that of DSE, since it has been shown that DS amounts are highly increased in these cases. Thus, the differential increase of these enzymes might provide direct evidence on tumor type and status.

\section{References}

1. Vynios DH, Karamanos NK and Tsiganos CP: Advances in analysis of glycosaminoglycans: its application for the assessment of physiological and pathological states of connective tissues. J Chromatogr B 781: 21-38, 2002.

2. Theocharis AD and Theocharis DA: High-performance capillary electrophoretic analysis of hyaluronan and galactosaminoglycan-disaccharides in gastrointestinal carcinomas. Differential disaccharide composition as a possible tool-indicator for malignancies. Biomed Chromatogr 16: 157-161, 2002.

3. Jayson G, Lyon M, Paraskeva C, Turnbull J, Deakin J and Gallagher J: Heparan sulfate undergoes specific structural changes during the progression from human colon adenoma to carcinoma. In Vitro 273: 51-57, 1998.

4. Theocharis AD, Tsara M, Papageorgacopoulou N, Karavias DD and Theocharis DA: Pancreatic carcinoma is characterized by elevated content of hyaluronan and chondroitin sulphate with altered disaccharide composition. Biochim Biophys Acta 1502: 201-206, 2000.

5. Karousou EG, Porta G, De Luca G and Passi A: Analysis of fluorophore-labelled hyaluronan and chondroitin sulfate disaccharides in biological samples. J Pharmaceut Biomed Anal 34: 791-795, 2004.

6. Wu X, Chen VW, Martin J, Roffers S, Groves FD, Correa CN, Hamilton-Byrd E and Jemal A: Subsite-specific colorectal cancer incidence rates and stage distributions among Asians and Pacific Islanders in the United States, 1995 to 1999. Cancer Epidimiol Biomarkers Prev 13: 1215-1222, 2004.

7. Stern R: Hyaluronan metabolism: a major paradox in cancer biology. Pathol Biol 53: 372-382, 2005.

8. Theocharis AD, Vynios DH, Papageorgakopoulou N, Scandalis SS and Theocharis DA: Altered content composition and structure of glycosaminoglycans and proteoglycans in gastric carcinoma. Int J Biochem Cell Biol 35: 376-390, 2003. 
9. Tsara ME, Theocharis AD and Theocharis DA: Compositional and structural alterations of proteoglycans in human rectum carcinoma with special reference to versican and decorin. Anticancer Res 22: 2893-2898, 2002.

10. Papadas TA, Stylianou M, Mastronikolis NS, Papageorgakopoulou N, Skandalis S, Goumas P, Theocharis DA and Vynios DH: Alterations in the content and composition of glycosaminoglycans in human laryngeal carcinoma. Acta Otolaryngol 122: 330-337, 2002.

11. Skandalis SS, Theocharis AD, Theocharis DA, Papadas T, Vynios DH and Papageorgakopoulou N: Matrix proteoglycans are markedly affected in advanced laryngeal squamous cell carcinoma. Biochim Biophys Acta 1689: 152-161, 2004.

12. Skandalis SS, Kletsas D, Kyriakopoulou D, Stavropoulos M and Theocharis DA: The greatly increased amounts of accumulated versican and decorin with specific post-translational modifications may be closely associated with the malignant phenotype of pancreatic cancer. Biochim Biophys Acta 1760: 1217-1225, 2006

13. Skandalis SS, Theocharis AD, Papageorgakopoulou N, Vynios DH and Theocharis DA: The increased accumulation of structurally modified versican and decorin is related with the progression of laryngeal cancer. Biochimie 88: 1135-1143, 2006.
14. Skandalis SS, Theocharis AD, Vynios DH, Papageorgakopoulou N, Hjerpe A, Karamanos NK and Theocharis DA: Cartilage aggrecan undergoes significant com-positional and structural alterations during laryngeal cancer. Biochim Biophys Acta 1760: 1046-1053, 2006.

15. Grigorieva E, Eshchenco T, Rykova VI, Chernakov A Zabarovsky E and Sidorov SV: Decreased expression of human D-glucuronyl C5-epimerase in breast cancer. Int J Cancer 122: 1172-1176, 2008

16. Maccarana M, Olander B, Malmstrom M, Tiedemann K, Aebersold R, Lindahl U, Li J and Malmstrom A: Chondroitinglucuronate C5-epimerase is indentical to SART2. J Biol Chem 281: 11560-11568, 2006

17. Nakao M, Shichijo S, Imaizumi T, Inoue Y, Matsunaga K, Yamada A, Kikuchi M, Tsuda N, Ohta K, Takamori S, Yamana H, Fujita $\mathrm{H}$ and Itoh K: Identification of a gene coding for a new squamous cell carcinoma antigen recognized by the CTL. J Immunol 164: 2565-2574, 2000. 